\title{
Lykaonia Bölgesi Kuzeydoğu Kesimi Tarihi ve Yerleşim Yerleri
}

\author{
Dr. Öğr. Üyesi İlker Işık \\ Selçuk Üniversitesi Edebiyat Fakültesi \\ Kültür Varlıklarını Koruma ve Onarım Bölümü \\ ilkerarkeo26@gmail.com
}

Öz

Lykaonia Bölgesi, genel hatları ile bugünkü Konya İli ve çevresini içine alan önemli bir antik yerleşim sahasıdır. Bölgede, tarihsel süreç içerisinde siyasi, ekonomik, sosyal ve kültürel anlamda birçok gelişme yaşanmış ve bunun neticesinde Lykaonia Bölgesi'nin sınırları da değişikliklere uğramıştır. Özellikle Roma Dönemi ve sonrasında bölgenin doğu sınırları Galatia Bölgesi'nde gösterilmiş ve bu geçişgenlik Lykaonia'nın diğer kesimlerine göre siyasal ve dinsel açıdan yapısal bir farklılık yaşanmasına neden olmuştur. Burada yer alan Savatra, Perta ve Kana antik kentleri gerek askeri gerekse dini bakımdan bölgenin sosyo-kültürel dokusunu yansıtan önemli yerleşim birimleri olmuştur. Roma Dönemi'nin önemli askeri sınır hattını oluşturan bu kentlerde Hristiyanlığın yayılması ile birlikte piskoposluk merkezleri konumuna yükselmişs stratejik değerlerini arttırmışlardır.

Anahtar Kelimeler: Lykaonia, Savatra, Perta, Kana, Bozdağ.

\section{The History of the Northeast Section of the Lykaonia Region and Its Settlements}

\begin{abstract}
Lykaonia region is an important ancient settlement area which includes today's Konya province and its surroundings with general lines. In the region, many historical, political, economic, social and cultural developments have taken place, and as a result, the borders of the Lykaonia region have undergone changes. Especially during the Roman period and afterwards, the eastern borders of the region were shown in the Galatia region, which led to structural and political structural differences compared to other parts of Lykaonia. The ancient cities of Savatra, Perta and Kana are important settlements reflecting the sociocultural texture of the region, both military and religious. In these ancient cities, which constitute the important military border line of the Roman period these ancient cities increased their strategic values in the position of bishops' centers with the spread of Christianity.
\end{abstract}

Keywords: Lykaonia, Savatra, Perta, Kana, Bozdağ 


\section{GİRIŞ}

Antik çağda Lykaonia olarak adlandırılan bölge, günümüzde büyük oranda Konya merkez ve ilçeleriyle birlikte Karaman, Aksaray illerinin de bir bölümünü içine almaktadır. Tarihi ve kültürel dokusu sebebiyle birçok medeniyeti bünyesinde barındırmış olan Konya ili, gerek kazı çalışmaları gerekse arkeolojik yüzey araştırmaları ile birçok bakımdan bilim insanları tarafından önemli bir çalışma sahası olmuştur. Bu denli derin bir tarih barındıran Konya ili sınırlarında yürütülen bu çalışmalar önemli veriler sunmakla birlikte halen bu geniş coğrafya içerisinde araştırılmayı ve teşhir edilmeyi bekleyen pek çok yerleşim yeri bulunmaktadır. Konya ilinin batı, orta ve güney kesimlerinde yer alan Seydişehir, Beyşehir, Çumra, Bozkır, Hadim ve Taşkent ilçeleri sınırlarında araştırmalar yürütülmüş ve buradaki yerleşim yerleri ile civardaki arkeolojik eserler tanım ve tasnif imkânı görmüştür. ${ }^{1}$ Bununla birlikte Konya'nın doğu kesimini ele alan etraflıca bir çalışma ise henüz yapılmamıştır. Bu doğrultuda, ilk kez 2017 yılında gerçekleştirdiğimiz ‘Bozdağ Milli Parkı Doğu ve Kuzey Kesimi Yüzey Araştırması' isimli arkeolojik yüzey araştırmamız ile Konya'nın doğu kesimini kapsayan ve burada yer alan, antik kayıtlarda adları geçen yerleşim alanlarının araştırılması, kronolojilerinin saptanması ve diğer araştırma sonuçları ile Konya tarihine ait tarihsel geçmişin boşluklarının doldurması amaçlanmıştır.

Bozdağ'ın eteklerinde kurulan antik yerleşim yerlerinin antik kayitlarda isimleri yer almakla beraber, ne zaman kuruldukları ve dönemsel faaliyetleri bir muamma olarak kalmıştır. Bu bölgede antik belgelerde adı geçen Perta, Kana ve Savatra antik kentleri bilinen en önemli yerleşim yerlerindendir. Bu şehir ve bölgelerin hepsi Lykaonia'nın doğusunda kalmaktadır. Bölgenin en tanınmışı ve tarihi kayıtlarda isminden en çok bahsettiren kenti ise bugünkü Konya'nın Selçuklu İlçesi, Yağlıbayat Mahallesi sınırları içerisinde bulunan Savatra (Sauatra / Soatra) antik kentidir.

Bu çalışmada öncelikli olarak, Lykaonia Bölgesi'nin kuzeydoğu kesiminin yerleşim alanları ile burada yer alan üç önemli kent olan Savatra, Perta, Kanna şehirlerine ait olan tarihi ve arkeolojik kaynaklar ön plana alınacaktır. Ayrıca, bu kentlerin bölge içerisindeki etkinliği uyarınca bölgenin doğu ve kuzey kesimlerindeki siyasi, askeri ve dini faaliyetler hakkında da bilgiler sunulmaya çalışılacaktır.

\section{LYKAONIA BÖLGESI'NINN TARİHI}

Lykaonia isminin kökeni Hititler'de Lukka'dan gelmektedir (Umar 1993: 526) ve Hitit belgelerinde Güney Anadolu'nun iç kısmı 'Luviya' olarak adlandırılmaktadır (French 1994: 69). Bölgenin ismini aldığı Luvi halkı (Luviler) MÖ 3000'li yıllardan Helenistik döneme kadar varlıklarını sürdürmüşlerdir. MÖ 2000'li yıllarda, Luvi ülkesi anlamına gelen 'Lukkawaniya' daha sonra Lykaonia'ya dönüşmüştür (Cate 1961: 195-200).

Bölge dönemlere göre, Hitit-Arzawa; Phryg-Assur-Kimmer; Grek-Pers; BergamaSeleukos; Roma-Galat; Roma-Part; Bizans-Sasani, Bizans-Arap ve Bizans-Türk mücadelelerinde önemli bir cephe görevi üstlenmiştir (Bahar 1997: 254-267). Dolayısıyla bölge pek çok medeniyete ev sahipliği yapmış, kültürel ve siyasal açıdan önemli bir merkez haline gelmiştir.

${ }^{1}$ H. Bahar, M. Yılmaz ve A. Baldıran'ın yapmış olduğu araştırmalar neticesinde bölge hakkında kapsamlı çalışmalar yürütülmüştür. 
MÖ 2. binde, Lykaonia'nın batısındaki Arzawa bölgesi dışında herhangi bir siyasi gü̧̈ bulunmamaktaydı (Tekin 1995: 37). Daha sonra Asur Koloni Çağı ve sınrasında bir güç olarak beliren Hititler ile beraber bölge Hitit İmparatorluğu'nun hakimiyeti altına girdi. Özellikle MÖ 1400-1200 yılları arasında Hititlere ait eserler söz konusu uygarlığın yoğun izlerini gözler önüne sermektedir (Bahar 1995: 221-222). Hitit-Arzawa hakimiyetinden sonra bölge Phryglerin hakimiyetine geçmiştir. Phrygler'in Anadolu'ya MÖ 1200-1100 yıllarında Trakya taraflarından geldikleri bilinmektedir. Konya'da bilhassa Alaadin Tepesi'ndeki kazılar sırasında pek çok Phryg eserinin bulunması Phryg kültürünün Roma dönemine kadar sürdüğünü göstermektedir (Akok 1970: 61). MÖ 7. yy başlarından sonra Phrygler devrinde önemli bir merkez olan Konya, Kimmer istilasından sonra Lydia'lllara geçmiştir (Baytak 2008: 41). Lydialıların egemenliği MÖ 6. yy'da Pers istilasıyla sona ererek Lykaonia bölgesi dahil Anadolu'nun büyük bir kısmı Persler'e teslim edilmiştir.

Lykaonia ve Kappadokia bölgeleri, Diadokhlar (Büyük İskender'in ardılları) dönemine değin tek elden idare edilmişlerdir. Diadokhlar döneminde ise Seleukoslar hakimyeti altında kalmıştır. Romalıların Anadolu'daki ilk münasebetleri Suriye kralı III. Antiochos'a karşı girişilen harekâtta söz konusu oldu. MÖ 190 yılında L.Cornelius Scipio idaresindeki Roma ordusu Makedonia ve Thrakia üzerinden Hellespontos'a (Çanakkale Boğazı) ve oradan da Küçük Asya'ya (Asia Minor) ayak bastı. Suriye ordusunu Scipio komutasında yenilgiye uğratan Roma, III. Antiochos'la MÖ 188'de yapılan Apameia Barışı sonrası bölgenin yönetimini müttefikleri Rhodos ve Pergamon arasında paylaştırdı. Roma politik hamlelerini dikkatle seçerek idaresi çok güç olan Anadolu topraklarını hemen işgal etmek yerine bölge hamisi konumunda kalmayı tercih etti. Roma'nın Anadolu coğrafyasındaki ilk eyaleti Apameia Barışı'ndan 55 yıl sonra MÖ 133'de Pergamon kralı III. Attalos'un ölümünün ardından ülkesini Roma'ya vasiyet etmesi sonrasında MÖ 129 senesinde mümkün oldu.

Seleukos kralı Antiochos'un Roma ordusuna yenilmesi sonrası bölge Romalılar tarafından Bergamalı II. Eumenes'e verilmiştir (Magie 1950: 19). MÖ 133 yılına gelindiğinde, Bergama Krallığı'nın son kralı II.Eumenes'in oğlu III. Attalos'un ölümüyle ilan edilen vasiyetinde krallığın toprakları Roma'ya bırakıldı. Fakat, Attalos'tan önceki kral II.Eumenes'in oğlu Aristonikos ile yapılan savaşta tutsak düşen Kappadokialı IV. Ariarathes'in çocuklarına Lykaonia bölgesi verilir.

MÖ 1. yy başlarında Marcus Antonius, Pamphylia, Pisidia, Phrygia ve Milyas'ın dahil olduğu Kilikia Eyaletini kurdu. Bu eyalet Lykaonia bölgesini de içine alarak Kappadokia'ya kadar da uzanmaktaydı (Gür 2007: 87). Dolayısıyla bölgenin MÖ 1 yy başlarında Kilikia Eyaleti'nde yer aldığı anlaşılmaktadır.

MÖ 40-39 yılından itibaren Marcus Antonius'un eyaletlerin statüsünü yeniden dizayn etmesiyle beraber Laodikea'lı Zeno'nun oğlu Polemo, bölgede yönetici olarak tayin edildi. Buna göre, Polemo başkent İkonium başta olmak üzere Lykaonia ile Kilikia'ya kadar uzanan bölgeyi hakimiyeti altına aldı (Strabon, Geographica, XIV .2. 24; Sayar 1994: 207). Ancak, MÖ 36 yılına gelindiğinde Marcus Antonius tekrar düzenleme yaparak, Galatia ile Lykaonia'nın bir kısmını son Galatia kralı Amyntas'a verdi (Magie 1950: 434). Amyntas'ın MÖ 25 yılında Hımanadlar tarafından pusuya düşürülüp öldürlmesi sonrasında Augustus (MÖ 27-M.S. 44) "Provincia Galatia" adıyla Lykaonia ve Galatia eyaletlerini birleştirmiştir (Sherk 1980: 958; Texier 2002: 446). Tiberius döneminde (M.S. 14-37) Galatia ile Kappadokia birbirinden ayrılırken (Özsait 1985: 99), Vespasianus (M.S. 69-79) döneminde gelindiğinde ise yeniden 
bu iki bölge birleştirilmiş, söz konusu süreçler içerisinde Lykaonia bu bölgelerin içerinde yer almıştır (Kaya 2000: 164; Bosch, 1967: 66).

Antoninus Pius (M.S. 138-161) Lykaonia'yı ayrı bir eyalete dönüştürmüştür. Böylece bölge kendi kendini yönetebilme makanizmasına kavuşmuştur (Özsait 1982: 391). Ancak, Diocletianus dönemine (M.S. 284-305) gelindiğinde Lykaonia Bölgesi, Galatia, Pisidia ve Isauria arasında pay edilmiştir (Broughton, 1975: 598; Bahar 1991: 95). Roma İmparatorluğu'nun geç dönemlerinde ve Bizans hakimiyeti zamanında Lykaonia'nın sınırları değişkenlik göstermeye devam etmiştir (Kurt, 2014: 29) İmarator Valens yönetiminde (M.S.364-378) bölge özerklik kazanmış (Hunger 1984: 55), I. Theodosius zamanında ise Lykaonia'nın güneyi Pisidia ve Pamphylia ile kesişme göstermiştir (Özsait 1985: 102).

\section{LYKAONIA BÖLGESI'NINN COĞRAFİ KONUMU}

Pek çok gezginin ve araştırmacının ilgisini çeken Konya'ya ilk geziler İ.Ö. 5 yy. da coğrafyacı Ksenophon'un gelmesiyle başlamıştır. Bölgenin batı sınırında, Ksenophon 'Anabasis' adlı eserinde Orta Anadolu'nun güneyinde yer alan Lykaonia'nın batısında Phrygia yer aldığından bahsetmektedir (Ksenophon 1998: I, 11-19). İ.S. 1 yy. da Strabon kente gelmiş ve kent hakkında kısa bir bilgi vermiştir. Bölgenin doğu sınırında Strabon, Lykaonia-Kappadokia sınırının Lykaonialılara ait Koropassos Köyü ile Kappadokialılara ait Garsaura (Aksaray) kenti arasında geçtiğini belirtmektedir (Strabon 2000: 65). Ayrıca Strabon kitabında bölgeden şu şekilde söz eder: Orkaorki ve Pitnissos'un etrafındaki bölgelerle Lykaonia Platosu soğuk, ağaçsız olup az su bulunduğu halde yabani merkeplerin otlak yeridir; hatta suyun bulunabildiği yerlerde de, halen suyun parayla satıldığı Soatra' da (Garsaura yakınında bir kasaba) olduğu gibi kuyular dünyanın en derin kuyularıdır (Strabon 2000: 65). Güney sınır zaman zaman Lykaonia şehirleri arasında dahil edilen Isauria'dan başlamak üzere güneydoğuya Dülgerler (Artanada)'e, buradan Göksu Irmağı (Kalykandos) sınır olmak üzere doğuya doğru gidilirken, buradan Karaman (Laranda)'ya bir yay çizilir ve son olarak bölgenin Kuzey Sınırı ise, Verinepolis'ten başlamak üzere batıya doğru Yağlıbayat (Savatra) ve oradan Ladik (Laodikeia-katekekaumene)'e, buradan da güney batıya doğru Beyşehir (Mistheia)'e bağlanır (Özlü 1994: 5). Texier ise 'Küçük Asya Coğrafyası, Tarihi ve Arkeolojisi' adlı kitabında Lykaonia'nın sınırlarından şöyle bahsetmektedir: Lykaonia doğusunda Kappadokia kuzey ve kuzey batısında Galatia ve Phrygia, doğu ucunda da Toros dağlarıyla birleşir. Burada Derbe ve Laranda şehirleriyle beraber bulunan en önemli şehir İkonium'dur (Texier 2002: 289).

\section{LYKAONIA BÖLGESİ KUZEYDOĞU KESİMI YERLEŞIM YERLERİ}

Lykaonia Bölgesi sahip olduğu konum dolayısıyla pek çok medeniyete ev sahipliği yapmış, üzerinde hakimiyet kurulan kültürlerin izlerini günümüze kadar taşımıştır. M.S. 372 yılında Valentinianus döneminde Lykaonia Bölgesi merkezi Ikonium olmak üzere tanzim edilmiştir. Bölgeye bağlı birçok antik kent bulunmakla beraber bu çalışma, Lykaonia bölgesinin kuzeydoğu kesiminde bulunan Savatra, Perta, Kana antik kentlerini kapsamaktadır (Harita 1).

\subsection{Savatra Antik Kenti (Yağlıbayat)}

Savatra antik kenti, Konya-Aksaray karayolunun 58. km.den sonra $12 \mathrm{~km}$. daha içeride bulunan Yağlıbayat Mahallesi içerisinde yer almaktadır. (Bildirici 2009: 209). 
08.05.2015 tarihli Konya Koruma Kurulu kararı ile Yağlıbayat Mahallesi sınırlarında bulunan Savatra Antik Kenti'nin 2863 sayılı yasa kapsamında I. ve III. derece arkeolojik sit alanı olmasına karar verilmiştir. Günümüzde bu yerleşim yerinde 19. yy.da Rus zulmünden dolayı Kırım'dan göç eden Tatar Türkleri ikamet etmektedir. Buraya ulaşım, asfalt bir yolla sağlanmaktadır.

Bozdağ'ın eteklerinde kurulan kent, kendisine komşu olan Perta ve Kana antik kentleri ile beraber Lykaonia Bölgesi'nin en doğu kesiminde yer almaktadır. Antik Çağ'dan günümüze kadar birçok yazar ve araştırmacı Savatra antik kentinden söz etmiştir. Strabon, Savatra (ya da Soatra) için, Garsaura (Aksaray) yakınında bir kasaba olduğunu, burada dünyanın en derin kuyularının bulunduğunu ve suyun bu kuyulardan çekildiğini söyler. Ayrıca su olmadığı halde, ülkede müthiş bir koyun yetiştiriciliğinin yapıldığını ve derin kuyulardan elde edilen suyun da burada parayla satıldığını belirtmektedir (Strabon, 2000: 65). Bir diğer seyyah Charles Texier ise Küçük Asya; Coğrafyası, Tarihi ve Arkeolojisi adlı eserinde Strabon'un tariflerini aktararak ve doğrulayarak Savatra'dan bahsetmektedir (Texier, 2002: 99).

Savatra kendi içinde yönetim mekanizması kurmuş olan önemli bir antik kenttir.

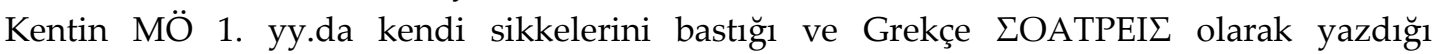
görülmektedir (Aulock, 1976: 73). Ramsay ise Roma'nın imparatorluk döneminde Savatra'nın Traianus Dönemi'nden (M.S. 98-117) beri bir darphaneye sahip olduğundan ve Antoninus Pius Dönemi'nde sikkeler üzerine Lykaonia Birliği yazısının eklendiğinden bahseder (Ramsay, 1960: 419). Savatra'da Roma dönemine ait birçok yazıt ele geçmiş ve W. M. Calder ve J. M. R. Cormack'ın yaptığı epigrafik çalışmalarla kent hakkında yeni bilgiler elde edilmiştir (Calder ve Cormack, 1962: 41-46).

Roma Dönemi'nde coğrafi sınırların değişmesi sebebiyle kent zaman zaman Galatia ve Lykaonia bölgesi içinde gösterilmiştir. Roma'nın erken dönem bölge teşkilatlanması esnasında Savatra, Galatia Bölgesi'nde bulunmaktaydı (Kadığlu 2009: 23; Kaya 2000: 164; Mitchell 1993 II: 155). M.S. 370/372 yıllarındaki yeni düzenlemeyle kent, Lykaonia Bölgesi'ne dahil edilmiştir (Bahar 2015: 291). Savatra genel itibariyle tarihi süreç içerisinde Lykaonia ile bağlantılı olup mühim bir geçiş güzergâhı olarak bilinmektedir (Belke-Restle 1984: 101). Özellikle antik kral yolu üzerinde bulunduğundan Sardes ve Gülek Boğazı arasındaki yolun geçiş noktalarından biri olarak bilinmektedir (Yükçü-Atağan 2011: 102).

Roma İmparatorluğu altında ihtişamlı bir görünüme kavuşan kent, Galatia-Lykaonia sınırını güvenlik altına alan stratejik bir askeri üs konumundadır. Şehrin bulunduğu Bozdağ eteğini boydan boya saran kuleler ile bu dağın doğu hattı boyunca uzanan kaleleri mevcuttur. Yerleşim planı açısından arazinin doğal durumuna uyarlanarak yapılmış olan, yaklaşık $45 \mathrm{~m}$. çapında olan bir tiyatro kısmen sağlam durumdadır. Burada bulunan bazı buluntular, Hellenistik dönemden günümüze kadar yerleşim gördüğünü göstermektedir (Karamut-Çay vd. 1985: 22). Bunun yanı sıra tiyatronun güney batısında büyük bir höyük alanı bulunmaktadır.

I. Şapur'un Büyük Pers İmparatorluğu'nu yeniden ayağa kaldırma hülyası ile giriştiği saldırılar neticesinde Sasani ordusu M.S. 240 yıllarında Kappadokia'yı el geçirerek Kızılırmak çevresinde konuşlandı. M.S. 251/252 yıllarına gelindiğinde Lykaonia ve Galatia sınırı arasında bulunan askeri kentlerden biri olan Savatra başta olmak üzere birçok kent Kral Şapur ve ordusu tarafından yağmalandı (Magie 1950: 694-698). Roma'nın doğu 
hattındaki savunma sistemini çökerten Şapur, M.S. 260 yılında İmparator Valerianus ile yaptığı şavaşı da kazanarak bölgeye iyice yerleşti. Ne var ki M.S. 272 yılında L. Domitius Aurelianus'un taarruzu sonucunda bölge toprakları tekrar Roma hakimiyeti altına girdi (Belke-Restle 1984: 54).

Bizans dönemine gelindiğinde ise önemli bir piskoposluk merkezi olan Savatra, 381 yılındaki İstanbul Konsili ve 451 yılındaki Kadıköy Konsili'ne temsilci göndererek önemini bu evre içerisinde de göstermiştir (Le Quien, 1901 I: 1083; Bahar 2015: 293). Savatra Hristiyan kimliğini Selçuklu dönemine kadar korumuş ve Katolik kayıtlarında piskoposluk merkezi olmaya devam etmiştir.

Çalışmamızda Savatra antik kentinin ortofoto çalışması yapılarak, kentin doğu eteğinde Roma dönemine ait olduğu düşünülen bir tiyatro kalıntısı, bir höyük ve bir kale kalıntısı bulunmuş ve bu mimari yapılar haritada gösterilmiştir. Ayrıca kent içerisinde bulunan seramik parçalarına da rastlanılmıştır. Seramik örnekler ağırlıklı olarak Roma Dönemi'ne ait olmakla beraber, Bizans Dönemi sırlı seramikleri ile Demir Çağı'na ait kaba örnekler de ele geçmiştir. (Resim 1, 2, 3, 4).

Savatra'daki antik Roma tiyatrosu, yerleşimin kuzeydoğusunda yer almakta olup hemen hemen sağlam durumdadır. Yerli halkın cavea üzerindeki krepisleri kısmen tahrip etmesi dışında orkestra, sahne ve parados duvarları bellidir.

Savatra antik kentinde bulunan höyük, tiyaronun hemen güneybatısında bulunmaktadır. Höyük üzerinde yapılan kaçak kazılara müdahale etmek amaıcıyla 1984 yılında İsmail Karamut başkanlığında Konya Arkeoloji Müzesi tarafından bir sezonluk kurtarma kazısı yapılmıştır. Ayrıca, Tiyaronun batısında bulunan bir alanda ele geçen heykeltraşlık eserler için bu noktada da kazı ve sondaj çalışmaları gerçekleştirilmiştir.

\subsection{Perta Antik Kenti (Giymir)}

Perta, Konya'nın yaklaşık 70 km kuzeydoğusunda Giymir Köyü yakınlarında yer alır. Kent, Peutinger'in tablosunda Archaleis'den 32 mil mesafede olarak gösterilmiştir (Ramsay 1960: 381). Kentin Roma döneminde kent meclisi olduğu, Bizans döneminin izlerini taşıdığı anlaşılmaktadır. Ne zaman terk edildiği bilinmemektedir. Kocaş'ta bulunan bir yazıtta kentin ismi ve Halk Meclisi olduğunu gösteren bir yazıt bulunmaktadır (MAMA VIII 1962: 263). Latince bir mil taşı da kentte bulunan eserler arasındadır. Bunların yanında Roma ve Bizans dönemine ait yaklaşık 30 civarında mezar taşı tespit edilmiştir (Bildirici 2009: 209).

Perta antik kenti Erken Hristiyanlık Devri'nden ititbren katolik listelerinde piskoposluk merkezi olarak geçmektedir. Kent, Lykaonia bölgesinin doğu sınırındaki diğer piskoposluk merkezi olan kentlerle birlikte ortak hareket ederek konsillere temsilci göndermiştir (Jones 1937: 36).

Çalışmalar esnasında Giymir yaylası'na ait yerleşim yerinin yakınında bir höyük tespit edilmiştir. Höyük ve çevresinde yoğun miktarda Roma ve Bizans ağırlıklı olmak üzere seramik örnekleri bulunmuştur. Höyük yakınlarında halk tarafından açılan kuyu içerinde kireç taşından yapılmış yaklaşık $2 \mathrm{~m}$. uzunluğunda Geç Roma asker kıyafetleri ile betimlenmiş bir stel bulunmuştur. Askerin üzerinde sırıt kısmına kadar uzanan sorguç görülmektedir. Bir elinde balta diğer elinde ise mızrak tutar şekilde betimlenmiştir. Bununla birlikte hanelerin avlu ve duvarlarında yazıt, ostotek ve mimari parçalar tespit edilmiştir(Resim 5, 6, 7, 8). 


\subsection{Kana Antik Kenti (Beşağıl)}

Kana, Konya'nın yaklaşık 60 km kuzey doğusunda Yağlıbayat köyü yakınlarındadır. Ramsay Kana'dan şöyle bahseder: “Kana'nın, Bizans listelerindeki sıraya göre Lykaonia'nin kuzey doğusunda, Savatra ile Perta'nın bulunduğu güzergah üzerinde olması icab eder. Ptolemaios'ta Adopissos'un yanına, güneyine koymakla bu fikri onaylamışoluyor. Bütün bu mülahazalar Hasan Dağın güney - batı eteklerine, Kara-ang Kapı'nın güneyine büyük Angos kalesinin bulunduğu tepeye işaret etmektedir. Bu havali için bir piskoposluk lazımdı ve bütün emareler bu piskoposluğun Kana olduğunu göstermektedir" (Ramsay 1960: 380). Kentin Roma Dönemi'nde kent meclisi olduğu, Bizans döneminde yaşandığ anlaşılmaktadır. Ne zaman terk edildiği bilinmemektedir. Burada MAMA kataloglarında kayda geçen önemli arkeolojik eserler mevcuttur. Bilhassa M.S. 3. ve 4. yüzyıllara ve sonrasına ait Geç Roma-Erken Bizans yazıtları ve mezar stelleri dikkati çekmektedir. Bizans dönemine ait 5. yüzyıla tarihlenen bir mezar taşı bulunmuş ve bu mezar taşının Rahip Domnos ve eşi Gaia olduğu ve rahibin de M.S. 381-451 yılları arası görevli olduğu sanılmaktadır. Ayrıca Roma ve Bizans dönemlerine ait 20 civarında mezar taşı tespit edilmiştir (Bildirici 2009: 209).

Yürütülen çalışmada Kana antik kentinde Roma dönemi ve sonrasına ait olduğu düşünülen bir kale tespit edilmiş, ortofoto çalışması yapılarak kalenin sınırları belirlenmiştir. Ele geçen seramikler genellikle Bizans ve Selçuklu dönemine ait özellikler göstermektedir. Özellikle sırlı seramiklerin çokça bulunması ve süsleme açısından farklı geometrik desenlerin kullanımı bu ayırda varmamızı sağlamaktadır (Resim 9, 10, 11).

\section{TARTIŞMA VE SONUÇ}

Antik dönemde Lykaonia Bölgesi genel anlamda günümüzdeki Konya ve ilçelerini içine alan bir bölgeyi kapsamaktadır. Pek çok medeniyetin uğrak noktası olan Lykaonia Bölgesi, merkezi stratejik konuma ve ayrı bir güce sahiptir. Dolayısıyla bölge, bugüne kadar pek çok araştırmacının ilgi odağı haline gelmiştir.

Gerçekleştirdiğimiz arazi ve ortofoto çalışmalarımız sonucunda Kültür Bakanlığ nezdinde tescil kaydına girecek olan yerleşim yerlerinin coğrafi konumu belirlenmiş, ayrıca bölgenin kuzeydoğu kesiminde yer alan Savatra antik kentinde Roma dönemi'ne ait antik bir tiyatro ile bir adet kale kalıntısı ve bir höyük kalıntısı; Perta'da bir höyük kalıntısı, yazıt parçaları ve Roma dönemine ait olduğu düşünülen bir asker steli; Kana da ise bir kale yapısı haritalandırılmış, ayrıca bölgede bulunan muhtelif seramik parçalarının da dökümantasyonu yapılarak bu veriler literatüre kazandırılmıştır. Böylece, gelecekte kazı çalışmaları yapmak isteyen bilim insanları için önemli verilerin ellerinde bulundurulması sağlanmıştır.

Genel itibariyle, bölgenin staratejik açıdan önemli bir askeri ve dini merkez olduğu ifade edilebilir. Bozdağ'ın eteklerinde kurulan söz konusu yerleşim yerlerinde tespit edilen kale kalıntıları ile Hristiyanlığın ilk dönemlerinde itibaren Kana, Perta ve Savatra kentlerinin piskoposluk merkezleri olması bunun birer göstergesidir.

Sonuç olarak, elde edilen veriler 1şığında Lykaonia Bölgesi ve kuzeydoğu kesiminin coğrafi özelliklerinin diğer kısımlarına nazaran daha dağlık bir yapı sahip olması askeri, ticari ve dini açıdan korunaklı bir özelliğe bürünmesine yol açmıştır. dağlık arazi içinden geçen yollar ticaretin artmasına neden olmuş; bununla birlikte savunma yapıları bakımından da son derece elverişli bir konum oluşmasına sebebiyet vermiştir. 


\section{SUMMARY}

The region called Lykaonia in ancient times fundamentally included the center and the districts of Konya and a particular region of Karaman and Aksaray cities. Researches were conducted in Seydisehir, Beysehir, Cumra, Bozkır, Hadim and Taskent districts in the western, central and southern parts of Konya province and the settlements in here and nearby archaeological sites have been defined and classified. However, a remarkable research in the eastern part of Konya has not been carried out yet. In this direction, in this study we aimed to determine which research on settlements in ancient records belong to the eastern part of Konya, to detect the chronologies and fill the gaps the historical past of Konya's history with other research through the first archaeological surface survey named 'Bozdağ National Park East and North Section Surface Survey'.

In 372, during the Valentianus period, Lycaonia region was transformed into a province, the central part of Konya. This study includes antique cities of Savatra, Perta and Kana in the northeastern part of the Lycaonia region, together with 20 ancient cities connected to the region. Savatra which was the most important ancient city in the northeast part is also called Yağlıbayat village, $12 \mathrm{~km}$ further from 58th $\mathrm{km}$ of the highway of KonyaAksaray. In general, it was linked with Lykaonia in the historical process and it was known as an important transit route. Since Trajan's time, Savatra had the right to own coins and became an important episcopate center in the Byzantine period and sent a representative to Istanbul Consulate in 381 and Kadıköy Council in 451, so Savatra also showed its importance during this phase. In our study, we found a theater remnant believed to belong to the Roman period on the eastern edge of the city, a mound and a castle remains thought to belong to the Ottoman period with an ortho-photo study of the ancient city of Savatra (Fig. 1, 2, 3, 4).

Perta, another city in the northeastern part of the Lykaonia Region, is located near the village of Giymir about $70 \mathrm{~km}$ northeast of Konya. It is understood that the city was a city council during the Roman period, bearing the traces of the Byzantine period. In our study, we found a mound, inscription remains and a soldier stele thought to be belonging to the Roman period and ceramic remains in the ancient city of Perta (Fig. 5, 6, 7, 8).

Kana is the third ancient city which has been located in our research area. It is located near Yağlıbayat village about $60 \mathrm{~km}$ north east of Konya. It is understood that the city was a city council during the Roman period and that it lived in the Byzantine period. In our study, structure of a castle thought to be belonging to the Roman period was found. Later, the borders of the castle were identified and determined with ortho-photo studies. In addition, ceramic residues were found in the area (Fig. 9, 10, 11).

As a result, the geography of Lykaonia region and northeastern part was determined, the socio-political and socio-cultural characteristics of the region were attempted to be made clear by the presence of the architectural constructions and ceramic remains through our study. 


\section{KAYNAKÇA}

Akok, Mahmut (1970). "Türk Tarih Kurumu Adına, Konya Alâeddin Tepesinde 1941 Yılında Yapılmış Olan Arkeolojik Kazıda Elde Edilen Mimari Buluntular".VII. Türk Tarih Kurumu Kongresi 25-29 Eylül 1970. Ankara.

Aulock, von Hans (1976). Münzen und Stadte Lykaoniens. Istanbuler Mitteilungen, Beiheft 16. Deutsches Archaologisches Institut Abteilung İstanbul: Tübingen.

Bahar, Hasan (1991). Isauria Bölgesi Tarihi. Doktora Tezi. Konya: Selçuk Üniversitesi.

Bahar, Hasan (1995). "Konya Çevresi Tarih Araştırmaları 1: Hititlerden Romallara Kadar Isauria Bölgesi". SÜ Fen-Edebiyat Fakültesi Edebiyat Dergisi (9-10): 219-241.

Bahar, Hasan (2005). Eskiçă̆ Tarihi (Ders Notları). Konya: Dizi Ofset.

Bahar, Hasan-Bizbirlik, A. (1997) "Tahrir Defterlerine Göre Akşehir-Ilgın Çevresindeki Osmanlı Yerleşmelerinin Arkeolojik Metodlarla Lokalizasyonu üzerine Bir Deneme". Konya: Ata Dergisi. (VII): 251-288.

Baytak, İsmail (2008). Lykaonia Bölgesi Konya Mezarları. Yüksek Lisans Tezi. Konya: Selçuk Üniversitesi.

Belke, Klause-Restle, Marcell (1984). Galatien und Lykaonien. Wien: Verlag der Österreichischen Akademie der Wissenschaften.

Bildirici, Mehmet (2009). Tarihi Su Yapıları. Ankara: Bayındırlık ve İskân Bakanlığı.

Bosch, Clemen Emile (1967). Quellen zur Geschichte der Stadt Ankara im Altertum: Ankara: Türk Tarih Kurumu Basımevi.

Broughton, T.R.S (1975). "Roman Asia Minor" An Economic Survey of Ancient Rome-IV. New York: Octagon Books.

Calder, W-Cormack, J. M. R (1962). Monuments from Lycaonia, The Psido- Phrygian Borderland, Aphrodisias (MAMA Vol. VIII). Manchester: .Manchester University Press.

Cassius, Dio (1914). Historia Romana. çev. E. Cary. New York: The Macmillan Co.

Cate, P.H.J. Houwing Ten (1961). The Luwian Population Groups of Lycia and Cicilia Aspera During the Hellenistic Period. Leiden: E.J. Brill.

French, David (1994). Isinda and Lagbe, Studies In The History and Topography of Lycia and Pisidia. Ankara: The Brits Institute of Ankara.

Gür, Selçuk (2007). İlk İnsandan Selçuklu'ya Anadolu Uygarlıkları ve Antik Şehirler. İstanbul: Alfa Yayınları.

Hunger, Herbert (1984). Tabula Imperi Byzantini. Wien: Verlag der Österreichischen Akademie der Wissenschaften.

Jones, Arnold Hugh Martin (1937). The Cities of the Eastern Roman Provinces. Oxford: At the Clarendon Press.

Kadığlu, Musa (2009). Eski Anadolu Uygarlıkları, Roma Dönemi'nde Anadolu. T.C. Kültür Bakanlığı, Türkiye Kültür Portalı Projesi. Arkeoloji ve Sanat Tarihi, Arkeoloji, Ankara.

Karamut, İ.- Çay, N., Yılmaz, Y (1985). Yağlıbayat Heykeltıraşlık Eserleri. Müze IV, Konya.

Kaya, Mehmet Ali (2000). Anadolu'daki Galatlar ve Galatya Tarihi. İzmir: Ege Üniversitesi Edebiyat Fakültesi Yayınları.

Ksenophon, (1998). Anabasis: Onbinlerin Dönüşü. çev. Tanju Gökçül. İstanbul: Sosyal Yayınlar.

Kurt, Mehmet (2014). Tarih, Kültür, Sanat, Turiz ve Tarım Açısından Uluslararası Sarayönü Sempozyumu. (24-26 Ekim), Konya. 28-44.

Le Quien, Michel (1901). Oriens Christianus. Wiesbaden: Otto Harrassowitz.

SEFAD, 2018 (40): 191-206 
Levick, Barbara (1967). Roman Colonies in Southern Aisa Minor. Oxford: Oxford at Clarendon Press.

Magie, David (1950a) Roman Rule in Asia Minor. I. Vol., Text, Princeton: Princeton University Press.

Magie, David (1950b) Roman Rule in Asia Minor. II. Vol., Text, Princeton: Princeton University Press.

Mama, (1962). Calder, William Moir, and James Maxwell Ross Cormack. Monuments from Lycaonia, the Pisido-Phrygian Borderland, Aphrodisias. «Monumenta Asiae Minoris Antiqua» [MAMA], 8. Manchester 1962.

Mitchell, Stephen (1993). Anatolia, Land, Men and Gods in Asia Minor: The Celts and the Impact of Roman Rule. I-II, Oxford-New York: Oxford University Press.

Özlü, İshak (1994). Klasik Çağda Lykaonia Bölgesi'nin Tarihi Coğrafyası. Doktora Tezi: Selçuk Üniversitesi.

Özsait, Mehmet (1982). Anadolu'da Roma Egemenliği. İstanbul: Görsel Yayınları.

Özsait, Mehmet (1985). Hellenistik ve Roma Devrinde Pisidya Tarihi. İstanbul: IÜEF Yayınları.

Ramsay, William (1960). Anadolu'nun Tarihi Coğrafyası. İstanbul: Milli Eğitim Basımevi: 380420.

Ramsay, William, Margaret A. (1906). Isaurian and East-Phrygian Art Studies in the History and Art of the Eastern Provinces of the Roman Empire. Aberdeen: Aberdeen University Press.

Sayar, Mustafa Hamdi (1994). "Antik Kilikya'da Şehirleşme". XII. Türk Tarih Kongresine Sunulan Bildiriler 12-16 Eylül 1994 (Ankara 1999). (I): 193-216.

Sevin, V. (2001). Anadolu'nun Tarihi Coğrafyası I, Ankara: Türk Tarih Kurumu Basımevi.

Sherk, R. K. (1980). "Roman Galatia: The Gouvernors from 25 B.C. to A. D. 114", Aufstieg und Niedergang der Römischen Welt, II, 7.2: 954-1052.

Strabon (2000). Antik Anadolu Coğrafyası. çev: Prof. Dr. Adnan Pekman., İstanbul: Arkeoloji ve Sanat Yayınları.

Tekin, Oğuz (1995). Eski Yunan Tarihi, İstanbul: İletişim Yayınları.

Texier, Charles (2002). Küçük Asya Coğrafyası, Tarihi ve Arkeolojisi. Ankara: Enformasyon ve Dokümantasyon Hizmetleri Vakfı.

Umar, Bilge (1993). Türkiye'deki Tarihsel Adlar, Türkiye'nin Tarihsel Coğrafyası ve Tarihsel Adları Üzerine Alfabetik Düzende Bir İnceleme. İstanbul: İnkılap Kitabevi.

Yükçü, Süleyman-Atağan, Gülşah (2011). Ortadoğu'da Zaman Tünelinde Ticaret. İzmir: Muhasebe ve Finans Tarihi Araştırmaları Dergisi: 86-109. 


\section{EKLER}

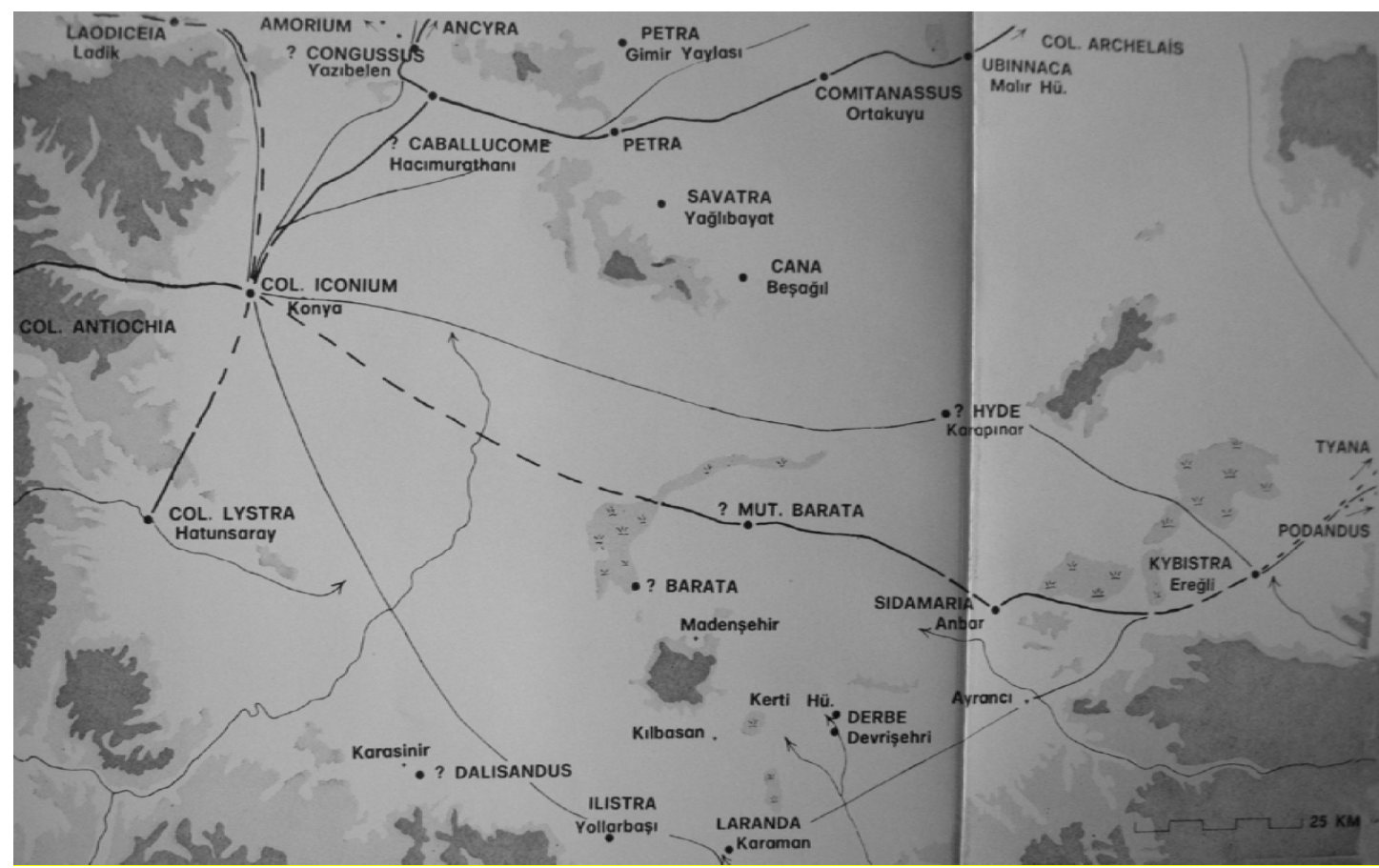

Hrt. 1: Lykaonia Bölgesi ve Kentleri (Aulock-1976)

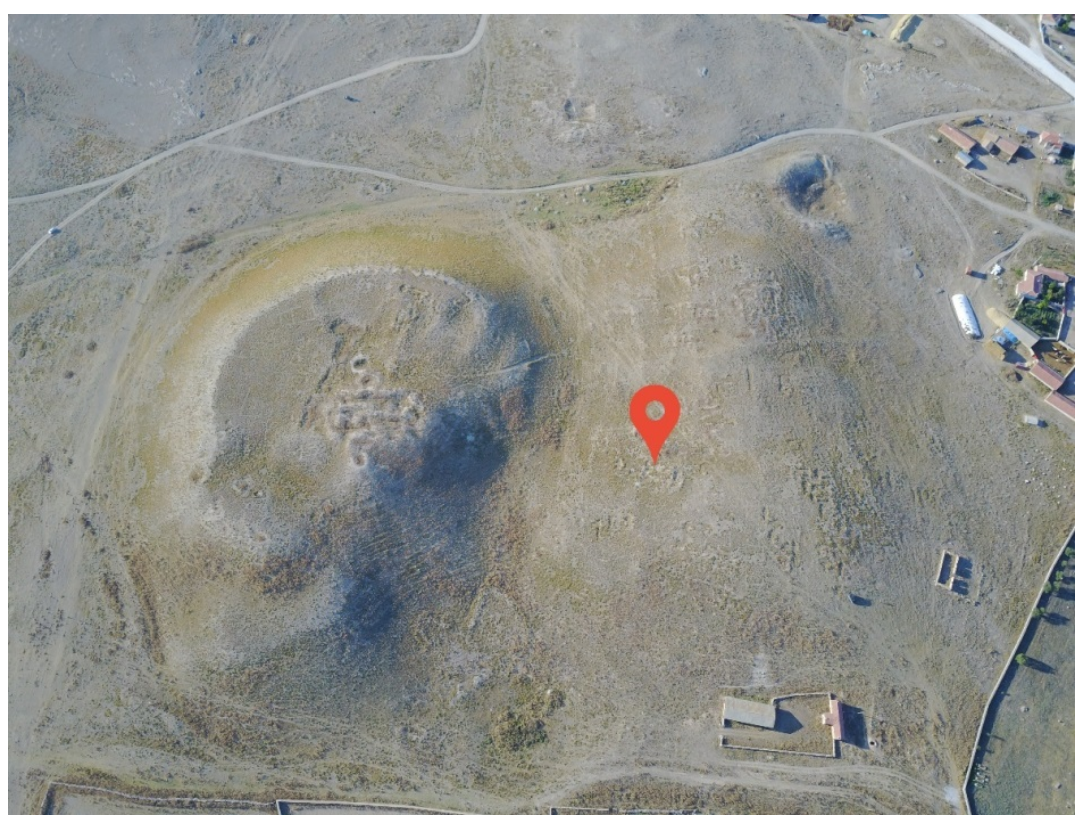

Resim 1(Fig.1.): Savatra Antik Kentinin Ortofoto Çalışması ile Genel Görünümü 

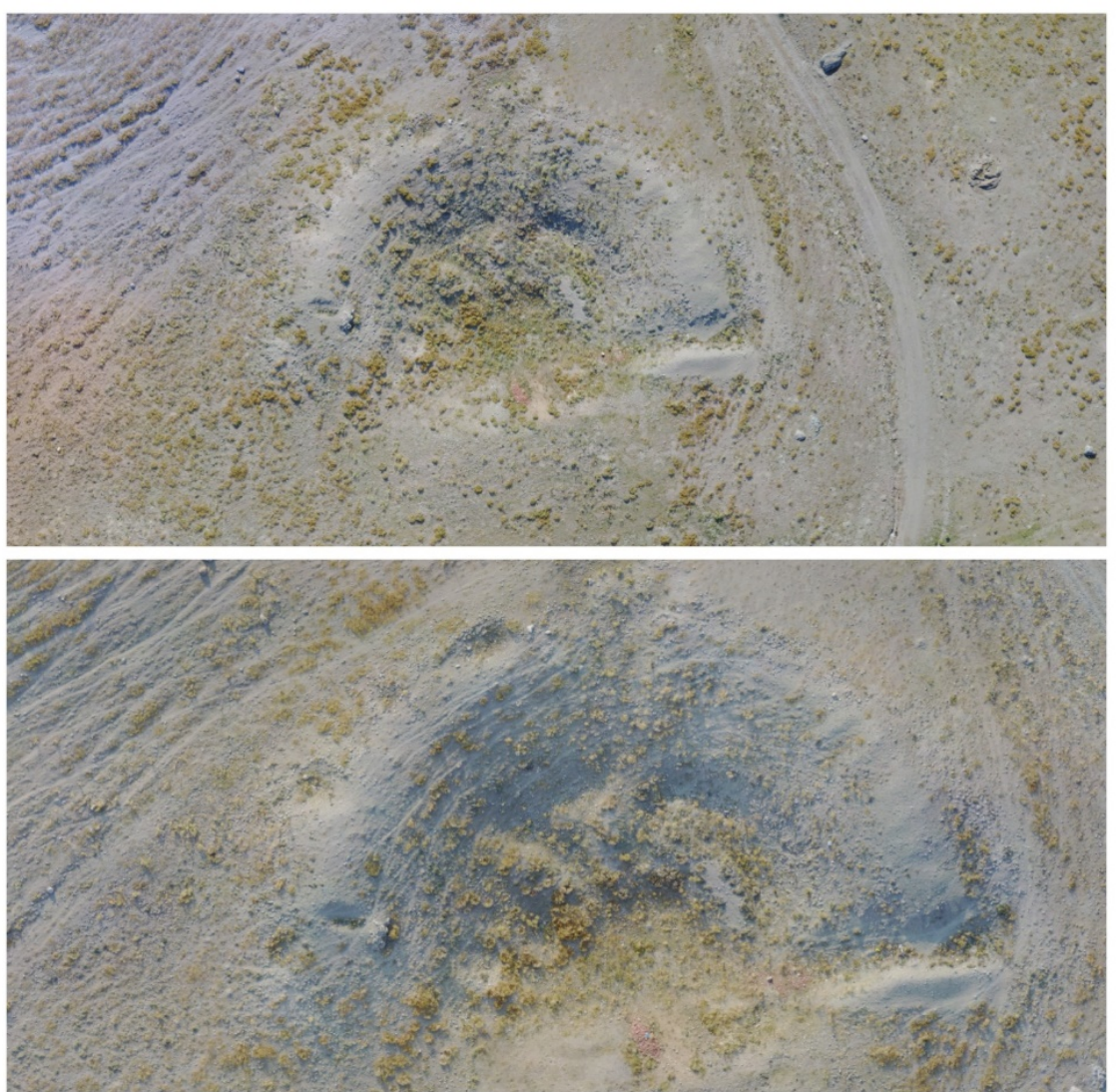

Resim 2 (Fig.2.): Savatra Antik Kentinde Bulunan Tiyatro

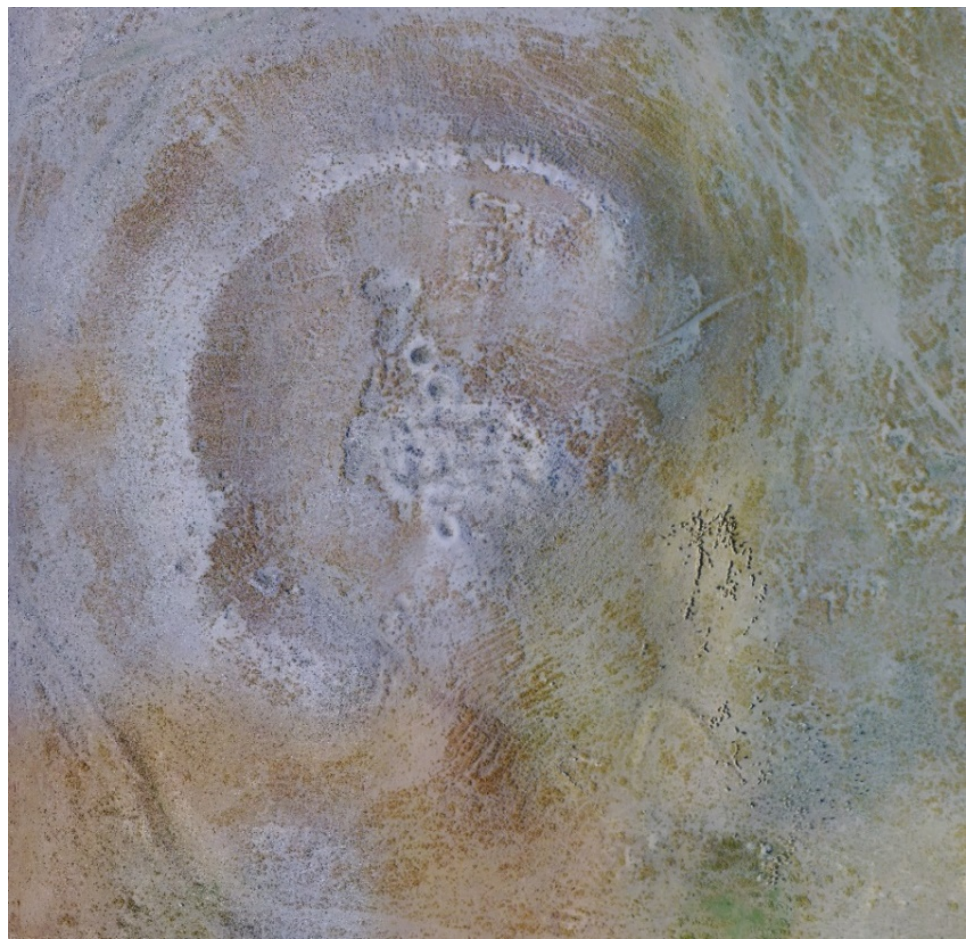

Resim 3 (Fig.3.): Savatra Antik Kentinde Bulunan Höyük 


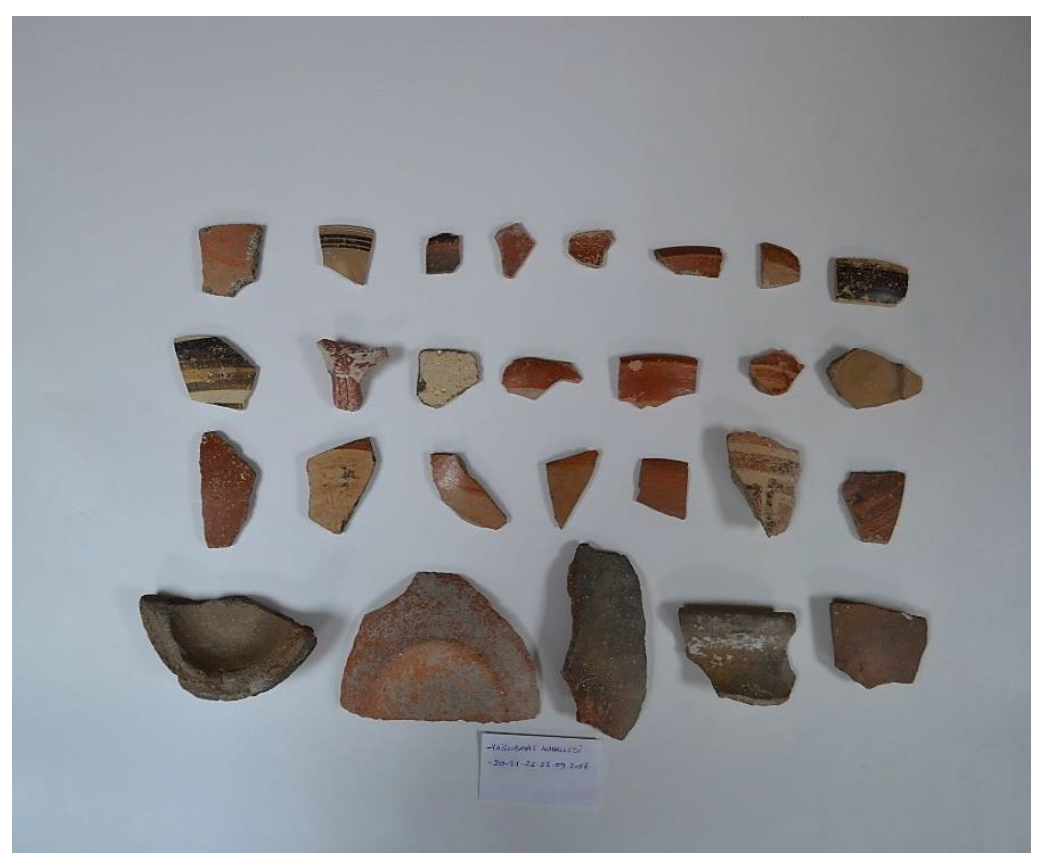

Resim 4 (Fig.4.): Savatra Antik Kentinde Bulunan Seramik Örnekler
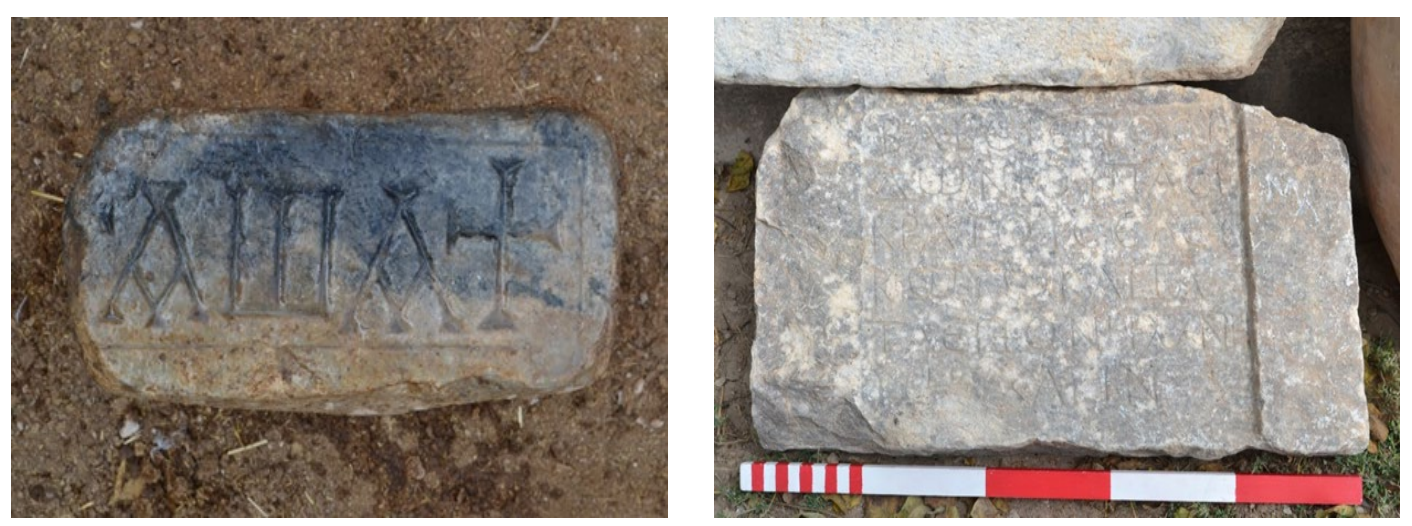

Resim 5 (Fig.5.): Perta Antik Kentinde Bulunan Yazıtlar 


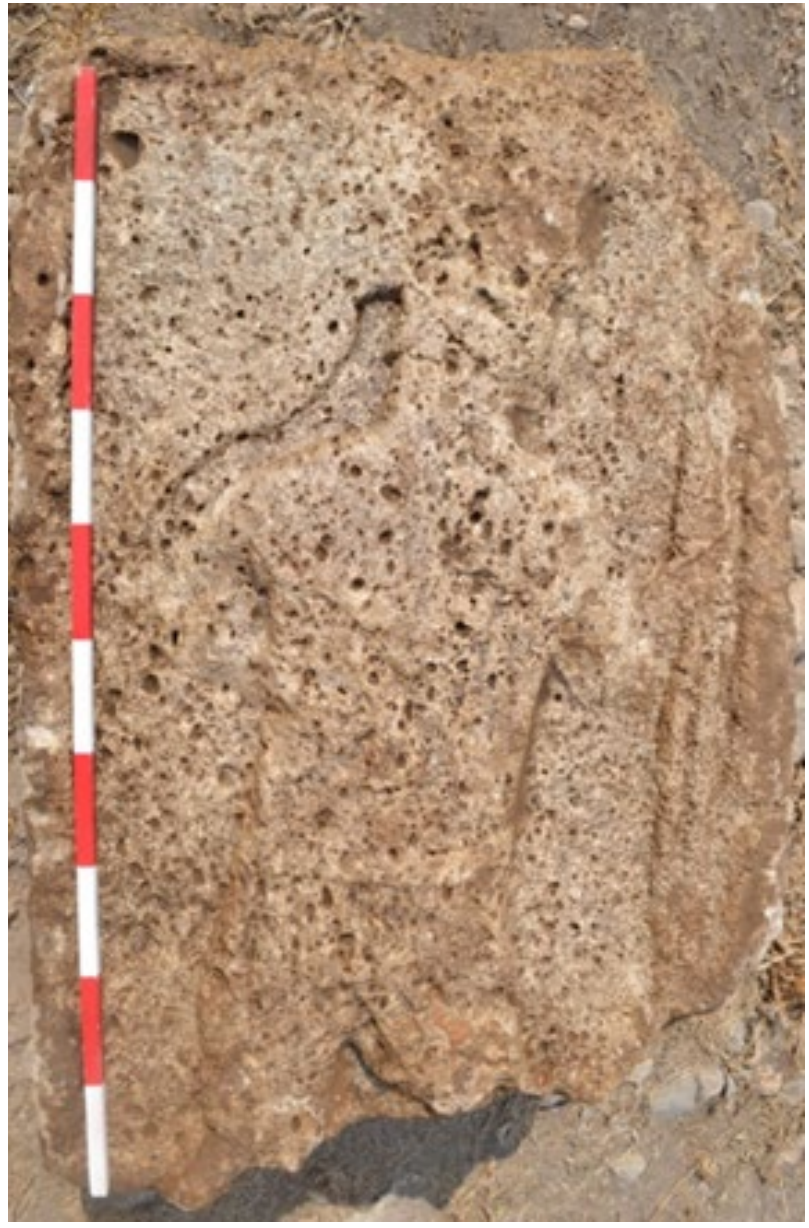

Resim 6 (Fig.6.): Perta Antik Kentinde Bulunan Asker Steli

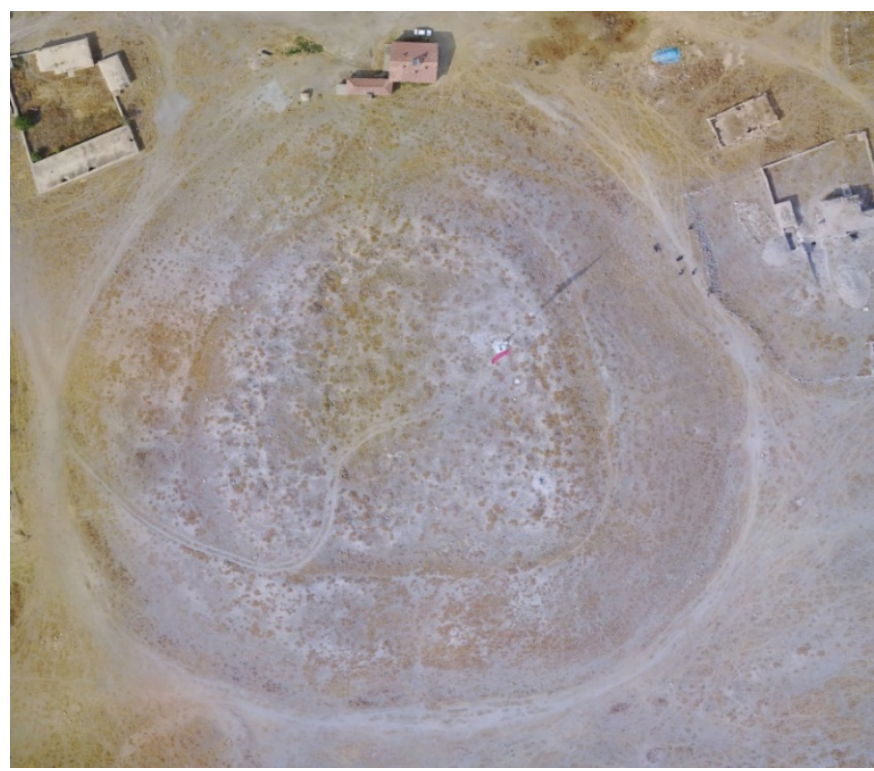

Resim 7 (Fig.7): Perta Antik Kentinde Bulunan Höyük 


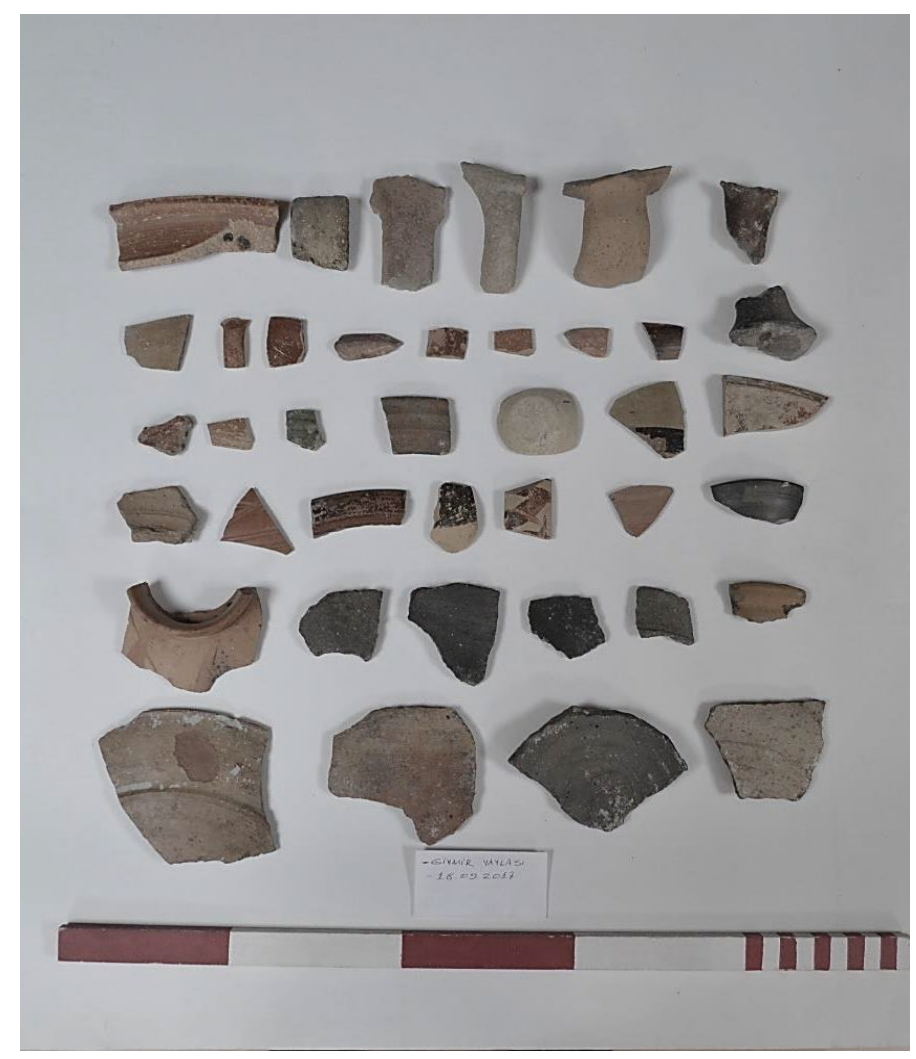

Resim 8 (Fig.8.): Perta Antik Kentinde Bulunan Seramik Örnekler

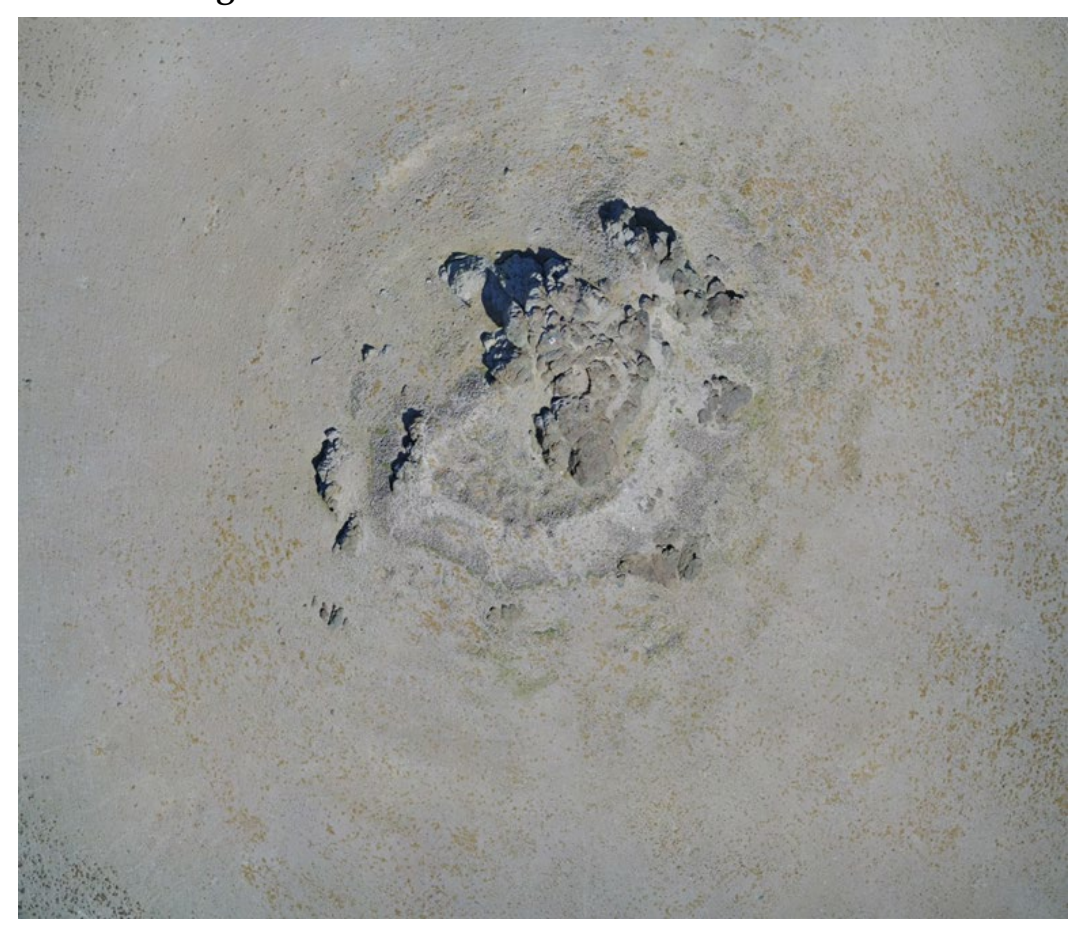

Resim 9 (Fig.9.): Kana Antik Kentinde Bulunan Kalenin Ortofoto Çalışması ile Görüntülenmesi 


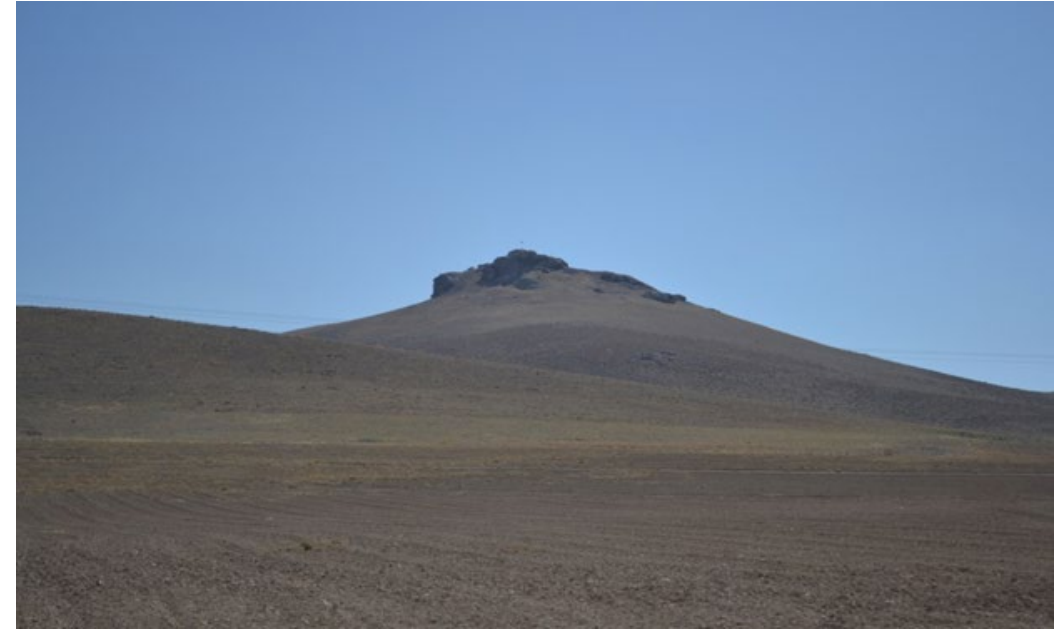

Resim 10 (Fig.11.): Kana Antik Kentinde Bulunan Kalenin Görüntüsü

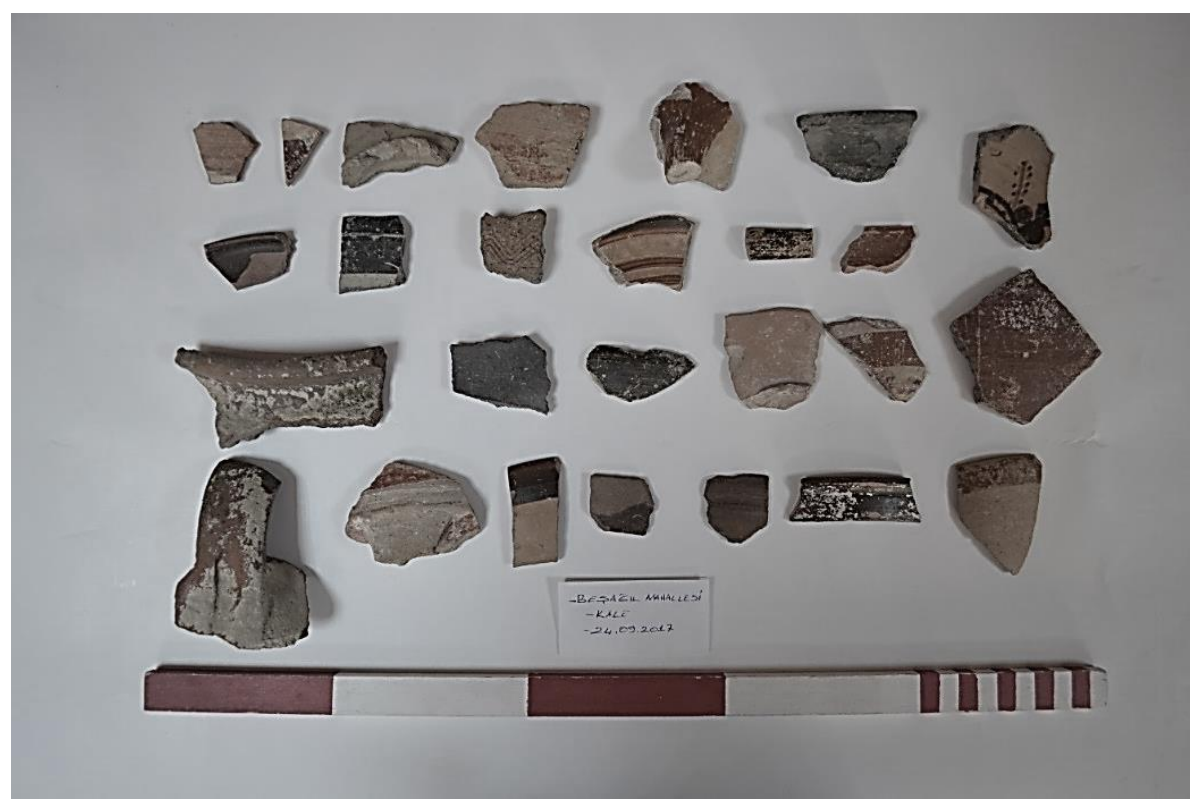

Resim 11 (Fig.11): Kana Antik Kentinde Bulunan Seramik Örnekler 